\title{
Infección oculta por el virus de la hepatitis B Aspectos clínicos epidemiológicos y moleculares
}

\author{
Occult hepatitis B virus infection \\ Clinical epidemiological and molecular aspects
}

\author{
Wilson Alfredo Ríos-Ocampo, Juliana Restrepo, Fabián Cortés, \\ Gonzalo Correa, María Cristina Navas • Medellín (Colombia)
}

\section{Resumen}

Propósito: La infección oculta por el virus de la hepatitis B se caracteriza por la presencia del genoma viral en muestras de suero y/o tejido hepático pero sin detección de antígeno de superficie. Los mecanismos de patogénesis no se conocen completamente. El propósito del presente artículo es discutir y describir los aspectos clínicos, epidemiológicos y moleculares más importantes de este tipo de infección.

Metodología: Se realizó una búsqueda de literatura en la base de datos PUBMED, de trabajos originales y revisiones de tema publicados entre 1979 y 2012. La búsqueda se realizó utilizando las palabras claves "Occult HBV infection, Epidemiology, clinical implications, mechamisms y outcome". Artículos relevantes citados en las publicaciones seleccionadas también fueron consultados.

Conclusiones: La identificación de casos de infección oculta por el virus de la hepatitis B y la descripción de la prevalencia es de importancia para la prevención de la transmisión de la infección y del desarrollo de hepatopatías terminales. La disponibilidad de métodos sensibles y específicos para la detección del genoma viral ha permitido explorar la epidemiologia. No obstante, aún son materia de estudio los mecanismos de patogénesis. (Acta Médica Colombiana 2013; 38: 143-153).

Palabras clave: hepatitis $B$, infección oculta, epidemiología, patogénesis, $H B s A g$.

\begin{abstract}
Objective: occult hepatitis B virus infection is characterized by the presence of the viral genome in serum and / or liver tissue samples but without surface antigen detection. The mechanisms of pathogenesis are not fully known. The purpose of this article is to discuss and describe the most important clinical, epidemiological and molecular aspects of this type of infection.

Methods: we performed a literature search in PUBMED database of original works and reviews of the subject published between 1979 and 2012. The search was performed using the keywords "occult HBV infection, epidemiology, clinical implications, mechanisms and outcome”. Relevant articles cited in the selected publications were also consulted.

Conclusions: the identification of cases of occult hepatitis B virus infection and the description of its prevalence is important in preventing transmission of the infection and the development of terminal hepatic diseases. The availability of sensitive and specific methods for the detection of viral genome has allowed us to explore the epidemiology. However, the mechanisms of pathogenesis are still under examination. (Acta Médica Colombiana 2013; 38: 143-153).
\end{abstract}

Keywords: hepatitis B, occult infection, epidemiology, pathogenesis, HBsAg.
Dr. Wilson Alfredo Ríos-Ocampo: Biólogo, Magister en Ciencias Básicas Biomédicas, Estudiante de Doctorado, Grupo de Gastrohepatología, Universidad de Antioquia; Dra. Juliana Restrepo: Residente de Cirugía, Universidad Pontifica Bolivariana; Lic. Fabián Cortés Mancera: Bacteriólogo, Magister en Ciencias Básicas Biomédicas. Grupo GI2B, Facultad de Ciencias Exactas, Instituto Tecnológico Metropolitano (ITM) Dr. Gonzalo Correa: Internista, Hepatólogo, Facultad de Medicina, Grupo de Gastrohepatología, Universidad de Antioquia. Unidad de Hepatología y Trasplante Hepático, Hospital Pablo Tobon Uribe; Dra. María Cristina Navas: Bacterióloga, Magister en Microbiología, Doctorado en Virología, Grupo de Gastrohepatología, Facultad de Medicina, Universidad de Antioquia. Medellín (Colombia).

Correspondencia. Dra. María Cristina Navas, Coordinadora Grupo de Gastrohepatología, Sede de Investigación Universitaria, Universidad de Antioquia. Medellín (Colombia)

E-mail: mcnavasn@gmail.com

Recibido: 13/VIII/2012 Aceptado: 26/VII/2013

\section{Introducción}

La infección por el virus de la hepatitis B (VHB) constituye un problema de gran impacto en salud pública a nivel mundial. Se estima que un tercio de la población mundial ha sido infectada por el VHB (2000 millones aproximadamente), de los cuales 350 millones de individuos presentan infección crónica la cual puede evolucionar a cirrosis y carcinoma hepatocelular (CHC) (1). Pese a la 
disponibilidad de una vacuna efectiva, este virus continúa siendo una importante causa de morbilidad y mortalidad, particularmente en países en vía de desarrollo.

La infección por el VHB es diagnosticada por la detección en sangre del antígeno de superficie del VHB (HBsAg, siglas del inglés: Hepatitis B s Antigen), el cual corresponde al marcador de tamizaje; adicionalmente, otros marcadores serológicos y virológicos como detección de anticuerpos contra la proteína Core del VHB tipo inmunoglubulina M (anti-HBc IgM) e inmunoglobulina G (anti-HBc IgG), antiHBs (anticuerpos contra el $\mathrm{HBsAg}$ ), antígeno e (HBeAg, del inglés hepatitis B e Antigen), ADN viral (carga viral) y niveles elevados de aminotransferasas (ALTs) son importantes para la clasificación del tipo de infección.

Después de la exposición al virus se estima hay un periodo de incubación de 1-6 meses. La evidencia de infección aguda corresponde a la detección del HBsAg y de anti-HBc (2). Otros marcadores como el HBeAg, títulos elevados del genoma viral (carga viral) y niveles altos de aminotransferasas (ALTs) pueden ser detectados. La infección aguda puede ser sintomática o asintomática siendo esta última una enfermedad subclínica que no es comúnmente diagnosticada (Figura 1).

Los casos en los cuales la infección se hace clínicamente evidente se caracterizan por síntomas tempranos como vómito, malestar general, anorexia y fiebre. Esta fase puede ser seguida por un episodio de ictericia que puede llevar o no a una hepatomegalia (3).
La resolución clínica de la infección se caracteriza por el descenso de la carga viral a valores negativos o no detectables, producción de anti-HBe, normalización de los niveles de ALTs y seroconversión de HBsAg a anti-HBs (3). Debido a la persistencia del genoma del VHB en los hepatocitos, actualmente se considera que el marcador anti-HBs no es marcador del aclaramiento viral (4). Por lo anterior individuos con resolución clínica pueden eventualmente desarrollar infección crónica (Figura 1). Cuando la infección evoluciona a un cuadro clínico persistente se define el tipo de infección crónica, la cual se caracteriza por la detección del marcador HBsAg por más de seis meses, la carga viral puede fluctuar, el HBeAg puede estar presente o no y los niveles de ALTs pueden estar normales o elevados dependiendo de la fase en la cual se encuentre la enfermedad.

Durante la infección crónica podrían identificarse dos fases: i) actividad inmune y ii) fase de portador inactivo (Figura 1).

La fase de actividad inmune se asocia con detección del HBsAg, HBeAg, niveles altos de ALTs, carga viral variable e inflamación del hígado con o sin fibrosis. La fase de portador inactivo se caracteriza por un perfil serológico $\mathrm{HBeAg}$ negativo y anti-HBe positivo, niveles bajos de ADN viral y mínima fibrosis hepática. Los síntomas durante la infección crónica pueden ser desde fatiga, dolor abdominal y ascitis hasta encefalopatía y pacientes con enfermedad hepática avanzada como cirrosis (3).

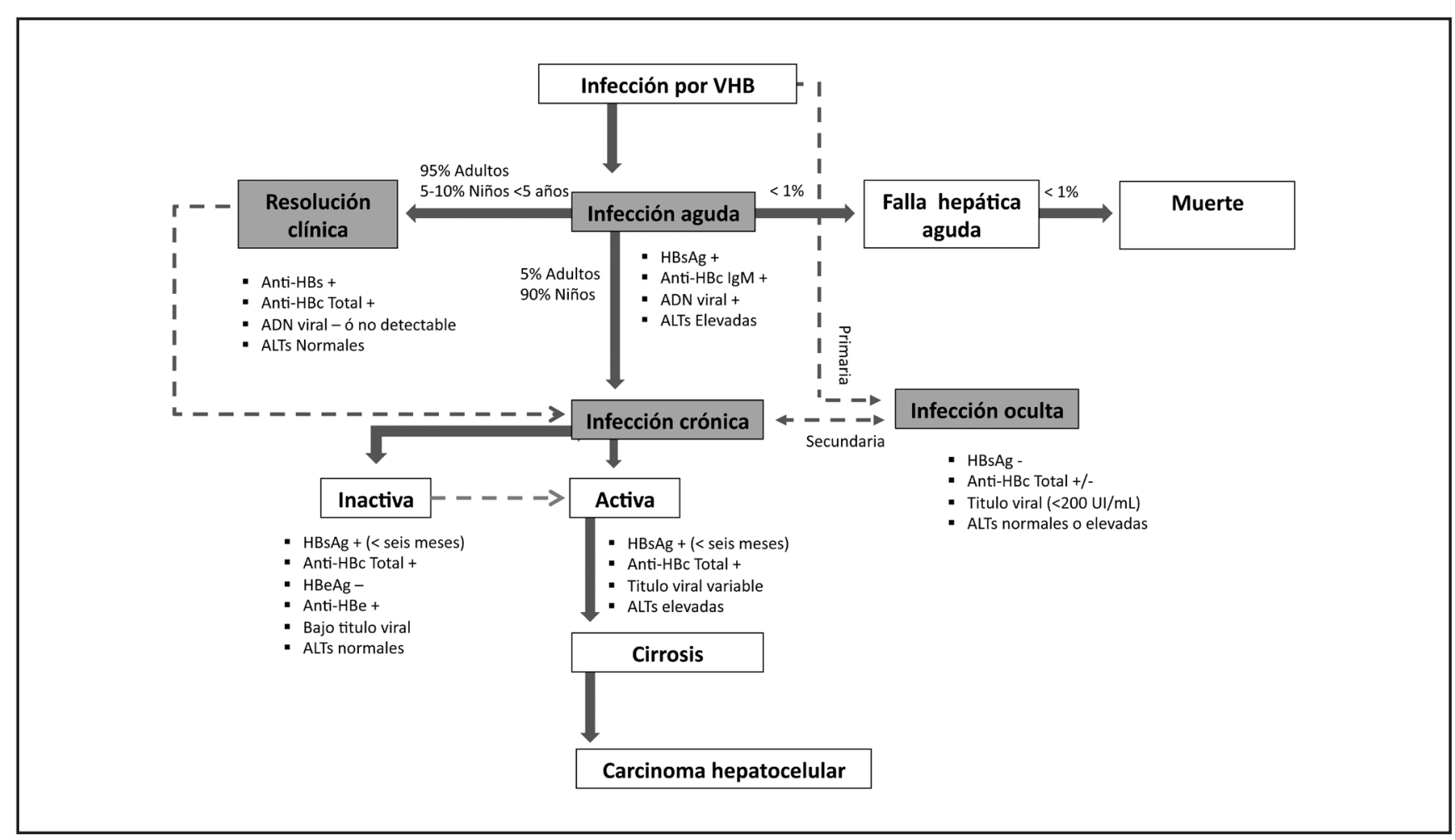

Figura 1. Historia natural de infección por VHB. Los recuadros grises indican los principales desenlaces clínicos durante la infección por VHB. Las flechas punteadas muestran los cambios sugeridos a la historia natural de la infección. 
Desde finales de los años 70 se describió un tipo de infección adicional correspondiente a individuos negativos para el marcador serológico HBsAg y presencia del genoma viral (5); esta particular forma de infección se conoce como infección oculta por VHB (OBI siglas del inglés: occut HBV infection) (Figura 1). Gracias al desarrollo en los últimos diez años de técnicas altamente sensibles para la identificación y estudio de casos de OBI, se han podido revelar aspectos clínicos y epidemiológicos que dan cuenta de la importancia de esta entidad (6).

\section{Definición de la infección oculta por VHB}

Loa criterios para definir la OBI son: i) No detección del HBsAg, ii) Presencia de anti-HBc, iii) carga viral menor a 200 Unidades Internacionales (IU)/mL $\left(10^{3}\right.$ Copias genoma/mL), iv) Presencia de ADN viral e intermediarios replicativos en tejido hepático, v) Presencia en algunos casos de anti-HBs. Este perfil correspondería a casos de OBI seropositiva (Tabla 1).

En el $20 \%$ de los casos de OBI no hay detección de los marcadores anti-HBc y/o anti-HBs; estos casos se conocen como OBI seronegativos (Tabla 1) y parecen ser equivalentes a los casos de infección oculta primaria descrita en el modelo de hepatitis B en marmotas (WHV, del inglés: Woodchuck hepatitis virus). En el anterior modelo experimental se ha demostrado la infección por VHB del tejido linfático, sin compromiso del hígado $(7,8)$. La OBI primaria es generada por cepas virales las cuales por medio de mecanismos que no se encuentran completamente esclarecidos, después de que infectan al individuo hacen que este curse una infección sin detección del HBsAg. Por el contrario, se ha denominado OBI secundaria, a los casos que inician como una infección aguda asintomática y/o infección crónica inactiva y que pierden posteriormente la expresión del HBsAg (Figura 1) (8).

Es de anotar, que existen casos de OBI denominados "falsa OBI" los cuales corresponden a infecciones producidas por virus que presentan mutaciones en el HBsAg las cuales producen un HBsAg modificado que no es reconocido por los anticuerpos utilizados en los kits de ELISA, pero que presentan una carga viral superior a $200 \mathrm{UI} / \mathrm{mL}\left(10^{4}-10^{5}\right.$ copias genoma/mL) (9).

En la actualidad se reconoce a la OBI como una entidad con implicaciones clínicas importantes, las cuales incluyen además del riesgo de transmisión de la infección por trasfusión sanguínea o trasplante de órganos, la exacerbación

Tabla 1. Definición de casos de infección oculta por VHB.

\begin{tabular}{|l|c|c|c|}
\hline \multirow{2}{*}{ Tipo de muestra } & \multirow{2}{*}{ Marcador } & \multicolumn{2}{|c|}{ Clasificación } \\
\cline { 3 - 4 } & & OBI Seropositiva & OBI Seronegativa \\
\hline Suero & $\begin{array}{c}\text { Anti-HBc/Anti-HBs } \\
\text { Carga viral }\end{array}$ & $\begin{array}{c}+/+ \\
<200 \mathrm{UI} / \mathrm{mL}\end{array}$ & $\begin{array}{c}-/- \\
<200 \mathrm{UI} / \mathrm{mL}\end{array}$ \\
\hline Tejido hepático & ADN-VHB & Positivo & Positivo \\
\hline
\end{tabular}

de la infección y la progresión a cirrosis y/o CHC (6). De ahí su importancia y el creciente interés al respecto en los últimos años.

\section{Aspectos clinicos de la infección oculta por VHB}

Una importante característica de la OBI es su impacto epidemiológico respecto al riesgo de trasmisión de la infección por VHB y el desarrollo de hepatopatías terminales, más aun cuando su diagnóstico es un evento casual bien sea porque unidades de sangre son tamizadas para VHB o porque los individuos presentan alteración del perfil serológico del hígado (niveles de ALTs) sin una etiología esclarecida.

La primera evidencia de transmisión de la infección por VHB con una unidad de sangre proveniente de un donante con OBI data de 1978 (10). Adicionalmente, Tabor y colaboradores evaluaron retrospectivamente sueros de donantes de sangre HBsAg negativos implicados en casos de hepatitis postransfusión; en este estudio se demostró la transmisión de la infección por VHB con una unidad de sangre proveniente de un donante con marcadores serológicos $\mathrm{HBsAg}$ negativo y anti-HBc positivo (5). Este tipo de transmisión fue posteriormente confirmado en chimpancés inoculados con sueros de individuos negativos para los marcadores serológicos pero con detección del genoma del VHB los cuales desarrollaron hepatitis viral aguda (11).

Debido al riesgo de transmisión de la infección por el VHB con unidades de sangre de donantes con OBI ha sido necesario implementar y desarrollar técnicas sensibles y específicas para la tamización de hepatitis B. El uso de anticuerpos monoclonales y policlonales anti-HBs en las pruebas de ELISA, así como, proteínas o antígenos recombinantes del VHB y pruebas de amplificación de ácidos nucleicos (NAT) han disminuido el riesgo residual de transmisión de VHB por trasfusión $(12,13)$.

Se ha demostrado que el riesgo de transmisión de la infección por VHB en trasplante de hígado a partir de donantes con perfil serológico HBsAg negativo y anti-HBc positivos es de 17-94\% (14). Adicionalmente, los individuos trasplantados pueden sufrir una reactivación de la infección a causa de la inmunosupresión en el periodo postrasplante (15). La transmisión de la infección por VHB en trasplante de órganos sólidos como riñón y corazón también ha sido documentada en casos de donantes con marcador anti-HBc positivo $(16,17)$.

Otro aspecto importante relacionado con OBI es la reactivación de la infección. La OBI podría considerarse como un estado de regulación negativa de la replicación viral y de la expresión de las proteínas virales (18). La reactivación de la infección se presenta en pacientes bajo condiciones de inmunosupresión inducidas por terapias y/o enfermedades que deprimen el sistema inmunológico. La reactivación clínica de la OBI ha sido observada en casos de enfermedades hematológicas, infección por el virus de 
la inmunodeficiencia humana (VIH) y trasplante de médula ósea, entre otros (16).

La OBI también ha sido descrita en casos de enfermedad hepática criptogénica (1.9 al 18.8\%). Incluso se ha demostrado que la OBI puede ser más frecuente que la infección por virus de la hepatitis $\mathrm{C}$ (VHC) en estos casos. Lo anterior fue observado por Berasain y colaboradores en una cohorte de pacientes con niveles elevados de transaminasas séricas. Adicionalmente, los casos de OBI presentaron con mayor frecuencia signos de cirrosis descompensada, comparados con pacientes con infección por VHB y detección de HBsAg (19).

\section{Diagnóstico de la infección oculta por el VHB}

La detección del genoma viral en muestras de suero o de tejido hepático es considerada la técnica de oro para el diagnóstico de la OBI. Las técnicas de elección son PCR (del inglés: Polimerase chain reaction) anidada y/o PCR en tiempo real, que puedan detectar menos de 10 copias del ADN viral. Además, se recomienda amplificar varios genes del VHB para incrementar la especificidad y realizar análisis de secuenciación de los productos amplificados para la confirmación del diagnóstico de OBI. Si no hay disponibilidad de técnicas de identificación de ácidos nucleicos, la presencia de anti-HBc podría ser utilizado como un marcador para la identificación de posibles casos de OBI (9).

\section{Epidemiologia de la infección oculta por el VHB}

La prevalencia de OBI ha sido estudiada en poblaciones con diferentes factores de riesgo como pacientes sometidos a hemodiálisis, con infección por VIH y/o VHC, usuarios de drogas psicoactivas por vía endovenosa y poblaciones con alta prevalencia de infección por VHB; además en pacientes con hepatopatía crónica criptogénica, pacientes con diagnóstico de $\mathrm{CHC}$, donantes de sangre y en población general. Estos estudios han aportado resultados disímiles de prevalencias de OBI (0-90\%) dependiendo de la población de estudio y de la sensibilidad y especificidad de la técnica utilizada para la detección del genoma de VHB, por lo que sus interpretaciones deben realizarse con precaución.

Samal y colaboradores sugieren que varios factores pueden influenciar potencialmente las tasas estimadas de OBI, entre los que se encuentran la población de estudio, tipo y número de muestras analizadas (20). Así mismo, otras limitaciones identificadas para establecer la prevalencia de la OBI es que no existen criterios unificados respecto a los cuadros clínicos de infección que deberían ser analizados $(7,21)$. Desafortunadamente, en la actualidad son pocos los estudios que utilizan iguales criterios de inclusión de pacientes, tipo de muestra y métodos de evaluación de ácidos nucleicos del VHB (20). La Tabla 2 presenta un resumen de las frecuencias reportadas de OBI en diferentes poblaciones de estudio. Sin embargo, se considera que los grupos de prin-
Tabla 2. Frecuencias de OBI reportadas en diferentes grupos de riesgo.

\begin{tabular}{|l|c|c|}
\hline Población de estudio & $\begin{array}{c}\text { Rango de } \\
\text { frecuencias (\%) }\end{array}$ & Referencias \\
\hline Pacientes con diagnóstico de hemofilia & $0-36$ & $(56-61)$ \\
Pacientes con infección por VIH & $0-89$ & $(62-66)$ \\
Usuarios de drogas psicoactivas por vía endovenosa & $2.7-45$ & $(67-69)$ \\
Pacientes con diagnóstico de CHC & $11-60.7$ & $(70-73)$ \\
Pacientes con enfermedad hepática criptogénica & $1.9-18.8$ & $(21,74,75)$ \\
Pacientes con infección por VHC & $0-51$ & $(7,76-78)$ \\
Donantes de sangre & $0-21.3$ & $(79-81)$ \\
\hline
\end{tabular}

cipal interés para el estudio de OBI son donantes de sangre, pacientes con enfermedad hepática criptogénica e individuos coinfectados con VHC y VIH. Lo anterior se debe al riesgo de transmisión de la infección, exacerbación de la misma y en el último caso debido a que algunos de los mecanismos que pueden dar explicación al desarrollo de OBI podrían ser atribuidos a eventos de inhibición de la replicación del VHB inducidos por el VHC y VIH.

En Colombia se conoce poco acerca de la prevalencia de la OBI. Existen cuatro estudios realizados en poblaciones de pacientes infectados por VIH y en donantes de sangre. El primer estudio incluyó una cohorte de 50 pacientes VIH positivos atendidos en un hospital de la ciudad de Medellín. Doce muestras HBsAg negativo/anti-HBc positivo fueron evaluadas para la detección del ADN del VHB, de las cuales sólo un caso fue positivo para detección del genoma viral por PCR (22). En un segundo estudio se analizaron muestras de suero de 103 pacientes VIH positivos atendidos en una institución de salud en la ciudad de Barranquilla. Del número total de muestras, seis casos presentaron anti-HBc positivo y HBsAg negativo; de éstos se logró confirmar la detección del genoma viral por PCR y cuantificación de la carga viral por PCR en tiempo real (23).

Respecto a la identificación de casos de OBI en donantes de sangre, Beltrán y colaboradores llevaron a cabo un estudio en cuatro bancos de sangre en Bogotá, Cali, Barranquilla y Valledupar. Un total de 129 muestras de suero de donantes HBsAg negativo/anti-HBc positivo fueron sometidas a pruebas NAT en pooles de seis muestras; sin embargo, en ningún pool de muestras se obtuvo amplificación del genoma del VHB. Aunque, en este estudio los autores no encontraron ningún caso de OBI ellos sugieren que la prevalencia de OBI puede estar alrededor de 3/125000 donaciones (13). De otro lado, Arroyave y colaboradores analizaron 207 muestras de suero de donantes de sangre con perfil HBsAg negativo/anti-HBc positivo por PCR convencional y posterior secuenciación del ORF S del VHB. Según los resultados preliminares de este estudio se reportó una frecuencia de $1.44 \%$ de OBI (24).

Recientemente, nuestro grupo determinó una frecuencia de $2 \%$ de casos de OBI en donantes de sangre en la ciudad de Medellín, Colombia. Fueron evaluadas 302 muestras 
de suero de donantes HBsAg negativo y anti-HBc positivo por PRC de los ORFs S, C y X. Los casos de OBI fueron confirmados por secuenciación del genoma viral y cuantificación de la carga viral; por lo anterior y en acuerdo con lo propuesto por Beltrán colaboradores se sugiere que aunque es posible observar una baja frecuencia de casos de OBI son necesarios más estudios para determinar la prevalencia de OBI (manuscrito en preparación). Teniendo en cuenta los anteriores estudios, es importante resaltar la importancia de realizar la tamización de las donaciones de sangre además del HBsAg con anti-HBc. Según datos del Instituto Nacional de Salud, se calcula que en Colombia, aproximadamente el $36 \%$ de las unidades de sangre recolectadas no son tamizadas para anti-HBc y sólo en una mínima proporción (8\%) se analizan para la detección de ácidos nucleicos (13).

\section{Organización genómica del VHB}

El VHB es un virus envuelto con un diámetro externo de 42 nanómetros $(\mathrm{nm})$. La cápside de simetría icosahédrica de
22-25 nm de diámetro. El genoma del VHB está constituido por una molécula de ADN circular de doble cadena parcial, es decir, con una de las cadenas incompleta (Figura 2). A esta molécula se le denomina crADN, del inglés: circular relaxed ADN. La cadena negativa consta de aproximadamente 3.2 Kilobases $(\mathrm{Kb})$ de largo y la cadena positiva presenta un tamaño variable entre 1.7-2.8 Kb. El genoma del VHB codifica siete proteínas a partir de cuatro marcos de lectura abierta (ORF, del inglés: Open Reading Frame) S, P, C y X (25) (Figura 2). Las funciones de las proteínas codificadas por el genoma del VHB se resumen en la Tabla 3.

Después de la adhesión, penetración y descapsidación de la partícula viral, el crADN es transportado al núcleo del hepatocito; en el núcleo la cadena positiva es reparada dando origen a un ADN de doble cadena completo, el cual se denomina ADN circular covalentemente cerrado (cccADN) (26). El cccADN permanece en el núcleo de los hepatocitos, además puede unirse a proteínas celulares, lo que permite su condensación y permanencia en el núcleo como un mini-

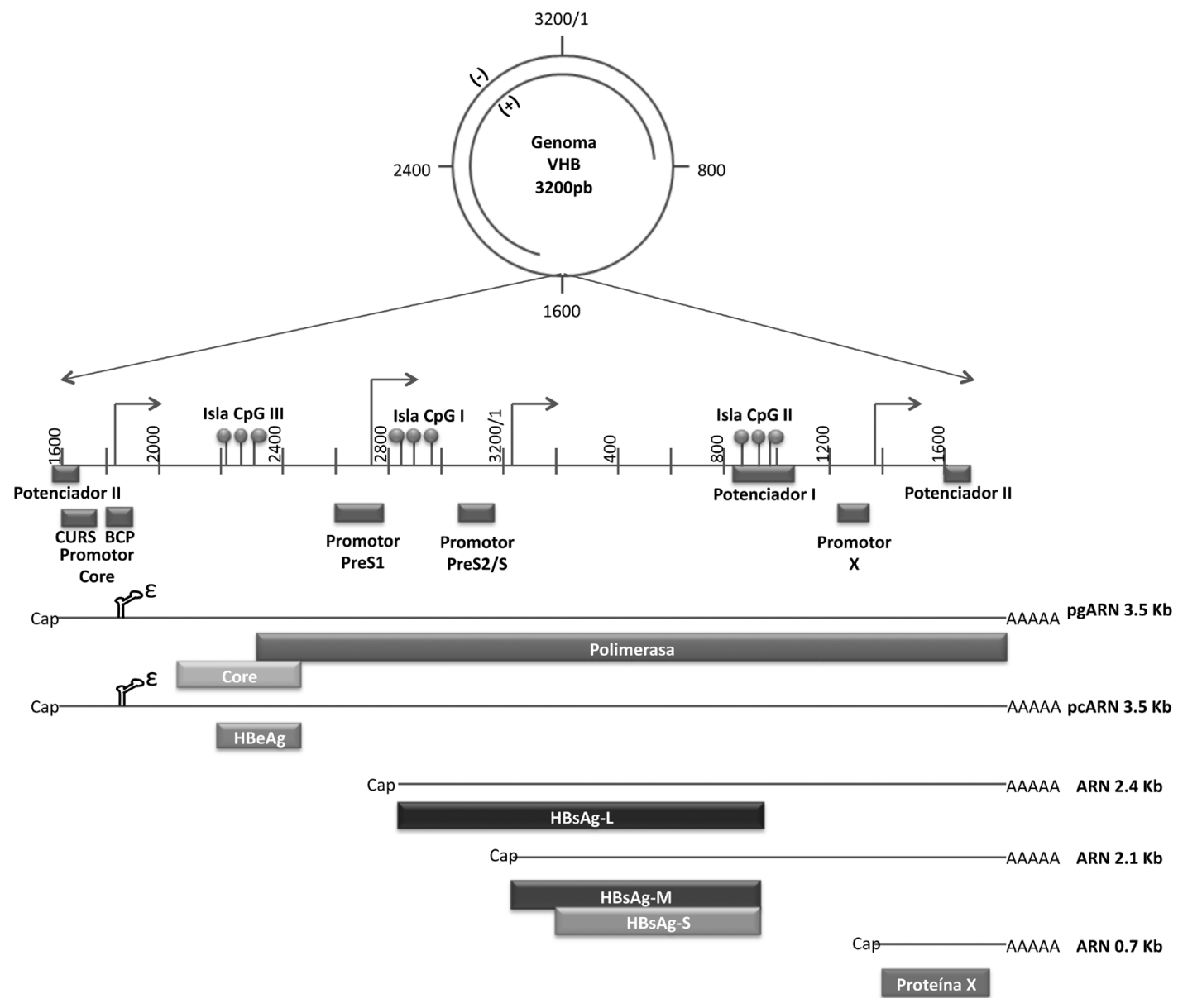

Figura 2. Organización genómica del VHB. El crADN del VHB se representa con un círculo de $3200 \mathrm{~kb}$; con los símbolos (-) y (+) se indican las cadenas negativa y positiva respectivamente. Las flechas superiores muestran la linearización del genoma en el nt 1600 . El genoma del VHB contiene 4 ORFs (indicados con las flechas en ángulo de $90^{\circ}$ ) bajo la acción de cuatro promotores (Promotor de Core, preSI, preS2/S y promotor de X) y dos regiones potenciadoras I y II representados con los rectángulos grises. Sobre el genoma linearizado se muestran tres islas CpG; la isla $C p G$ I se expande a través del codón de inicio del gen $S$, la isla CpG II sobre el potenciador I y la isla CpG III en el codón de inicio del gen de la polimerasa. En la parte inferior se presentan los 5 ARNs mensajeros transcritos y las proteínas codificadas a partir de cada uno. 
Tabla 3. Proteínas codificadas por el VHB.

\begin{tabular}{|l|l|l|}
\hline ORF & \multicolumn{1}{|c|}{ Proteína (Sigla) } & \multicolumn{1}{c|}{ Función } \\
\hline $\mathbf{S}$ & $\begin{array}{l}\text { Antígeno de superficie (HBsAg) } \\
\text { forma: Mayor (L), Medio (M) y } \\
\text { Pequeño (S) }\end{array}$ & $\begin{array}{l}\text { Permiten la adhesión y pene- } \\
\text { tración de la partícula viral a la } \\
\text { célula hospedera. } \\
\text { Blanco de respuesta inmuno- } \\
\text { lógica }\end{array}$ \\
\hline $\mathbf{P}$ & Polimerasa viral & $\begin{array}{l}\text { ADN Polimerasa, transcriptasa } \\
\text { reversa (RT) y ARNasa H }\end{array}$ \\
\hline $\mathbf{C}$ & Core (Antígeno Core: HBcAg) & $\begin{array}{l}\text { Subunidad estructural de la } \\
\text { cápside viral }\end{array}$ \\
\hline $\mathbf{X}$ & Antígeno e (HBeAg) & $\begin{array}{l}\text { Se sugiere como inmunomo- } \\
\text { dulador }\end{array}$ \\
\hline
\end{tabular}

cromosoma. La cadena negativa del cccADN sirve como molde para la transcripción de 5 ARNs mensajeros virales, este proceso es llevado a cabo por la ARN polimerasa celular tipo II. Los transcriptos genómicos son el ARN precore (pcARN) y el ARN pregenómico (pgARN). El pcARN codifica el HBeAg y el pgARN codifica la proteína Core y la polimerasa viral; además, el pgARN sirve de molde para la síntesis de nuevos genomas. Los transcriptos subgenómicos de $2.4 \mathrm{~kb}$ y $2.1 \mathrm{~Kb}$ codifican para la síntesis del HBsAg como se explicará más adelante. El fragmento subgenómico de 0.7 $\mathrm{Kb}$ codifica la proteína $\mathrm{X}(\mathrm{HBx})$.

El ORF S permite la síntesis del HBsAg. Este gen está compuesto por tres segmentos (pre-S1, pre-S2 y S) a partir de los cuales se generan tres tipos de HBsAg: mayor (HBsAgL), Mediano (HBsAg-M) y Pequeño (HBsAg-S) (Figura 3). Las proteínas HBsAg L, M y S tienen una región común, altamente conservada que es reconocida por los anticuerpos neutralizantes generados por la vacuna o por la infección natural, a la cual se le denomina determinante "a" (Figura 4). Esta región es considerada el epítope más importante para la respuesta inmune de linfocitos B; por tanto, cepas del VHB con sustituciones en esta región podrían evadir el reconocimiento de anticuerpos neutralizantes y eventualmente ser seleccionadas durante el transcurso de la infección (27).

El ORF Core está compuesto por las regiones pre-Core y Core (pre-C/C), esta región codifica el $\mathrm{HBeAg}$ y la proteína Core o proteína de la cápside. La transcripción de este gen está regulada por el promotor Core que posee un elemento denominado promotor basal de Core (BCP, del inglés: Basal Core Promoter) y un elemento conocido como secuencia reguladora corriente arriba de $\mathrm{BCP}$ (CURS, del inglés: $\mathrm{BCP}$ upstream regulatory sequence) (28).

\section{Aspectos moleculares de la infección oculta por VHB}

Los mecanismos de patogénesis de la OBI propuestos incluyen: i) variabilidad genética del VHB, ii) integración del genoma viral al genoma celular, iii) regulación transcripcional del minicromosoma por mecanismos epigenéticos, iv) respuesta inmune del hospedero y v) coinfecciones por el VIH y el VHC. La mayoría de estudios realizados hasta el momento han aportado evidencias indirectas de las estrategias de patogénesis responsables de esta patología (Figura 5).

\section{Variabilidad genética del VHB y asociación con OBI}

Numerosas mutaciones han sido descritas en los ORF $S$ y Core que pueden llevar a modificaciones antigénicas y alteraciones en el nivel de síntesis de las proteínas del VHB y del pgARN; esto se podría asociar con la no detección de antígenos virales mediante la prueba de ELISA, como se describe en casos de OBI y a una baja tasa de replicación (Figura 5) (7).

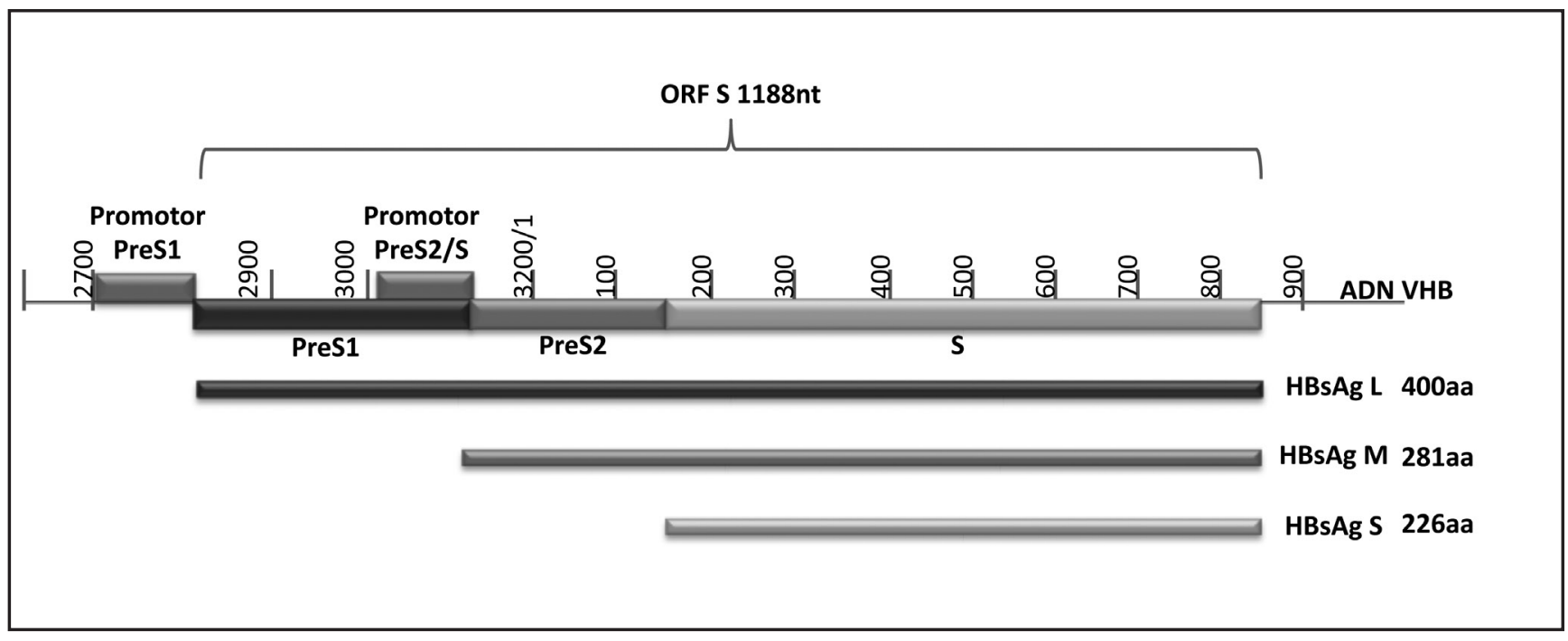

Figura 3. Representación esquemática del ORF S. Se presentan los tres segmentos genómicos preS1, preS2 y S, a partir de los cuales se sintetizan las proteínas L, M y S del HBsAg de 400, 281 y 226 aminoácidos, respectivamente (Kohno y col, 1996), bajo la acción de los promotores indicados en gris preS1 y preS2/S. 


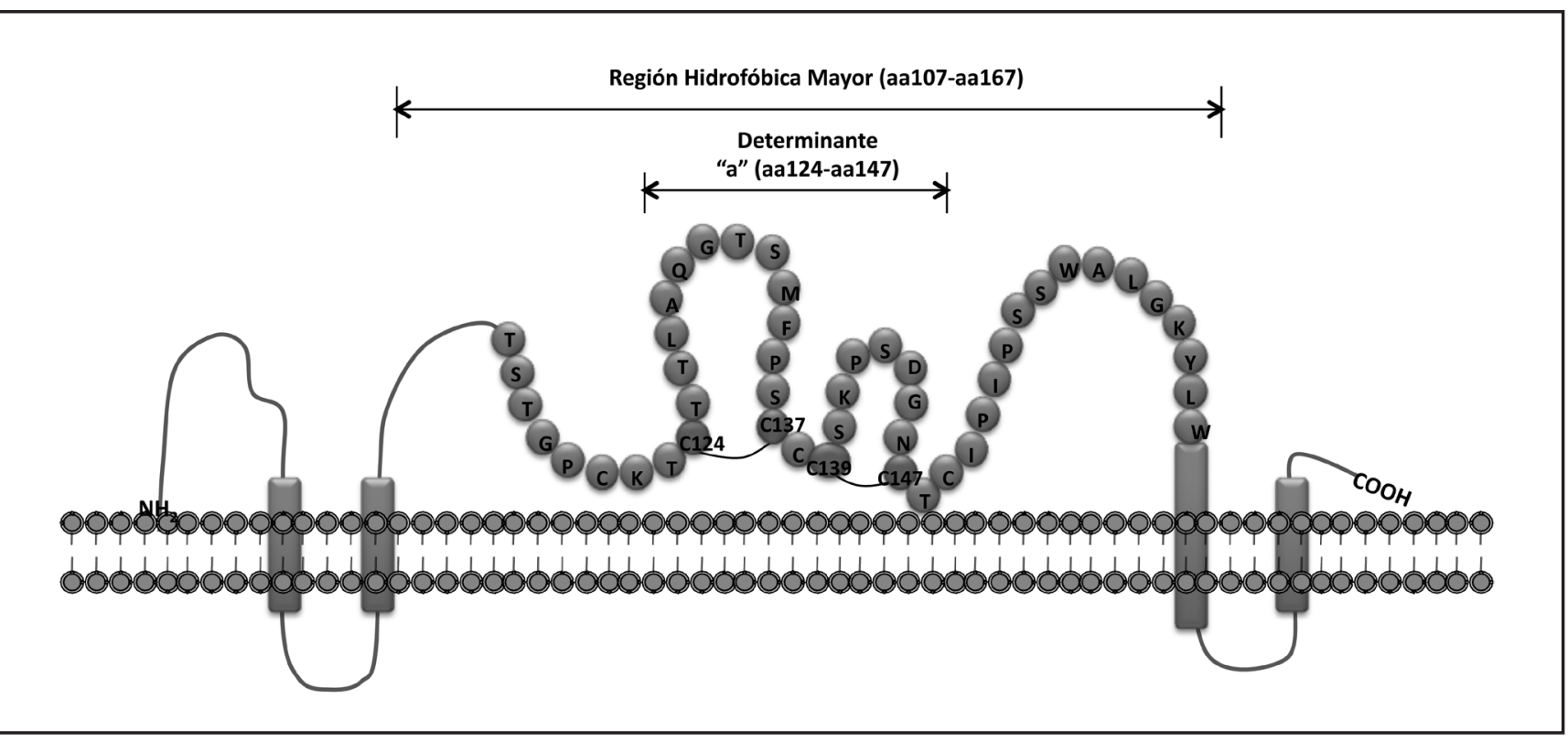

Figura 4. Estructura secundaria propuesta del HBsAg (L). La Región Hidrofóbica Mayor (aminoácidos 107 a 167) y el determinante "a” (aminoácidos 124 a 147) se representan con círculos con el nombre del respectivo aminoácido (código de una letra). El determinante "a" es el epítope inmunodominante, el cual es mantenido por dos puentes disulfuro C124-C137 y C139-C147. Adaptado de Fields Virology $5^{\text {th }}$ ED, (C)2007.

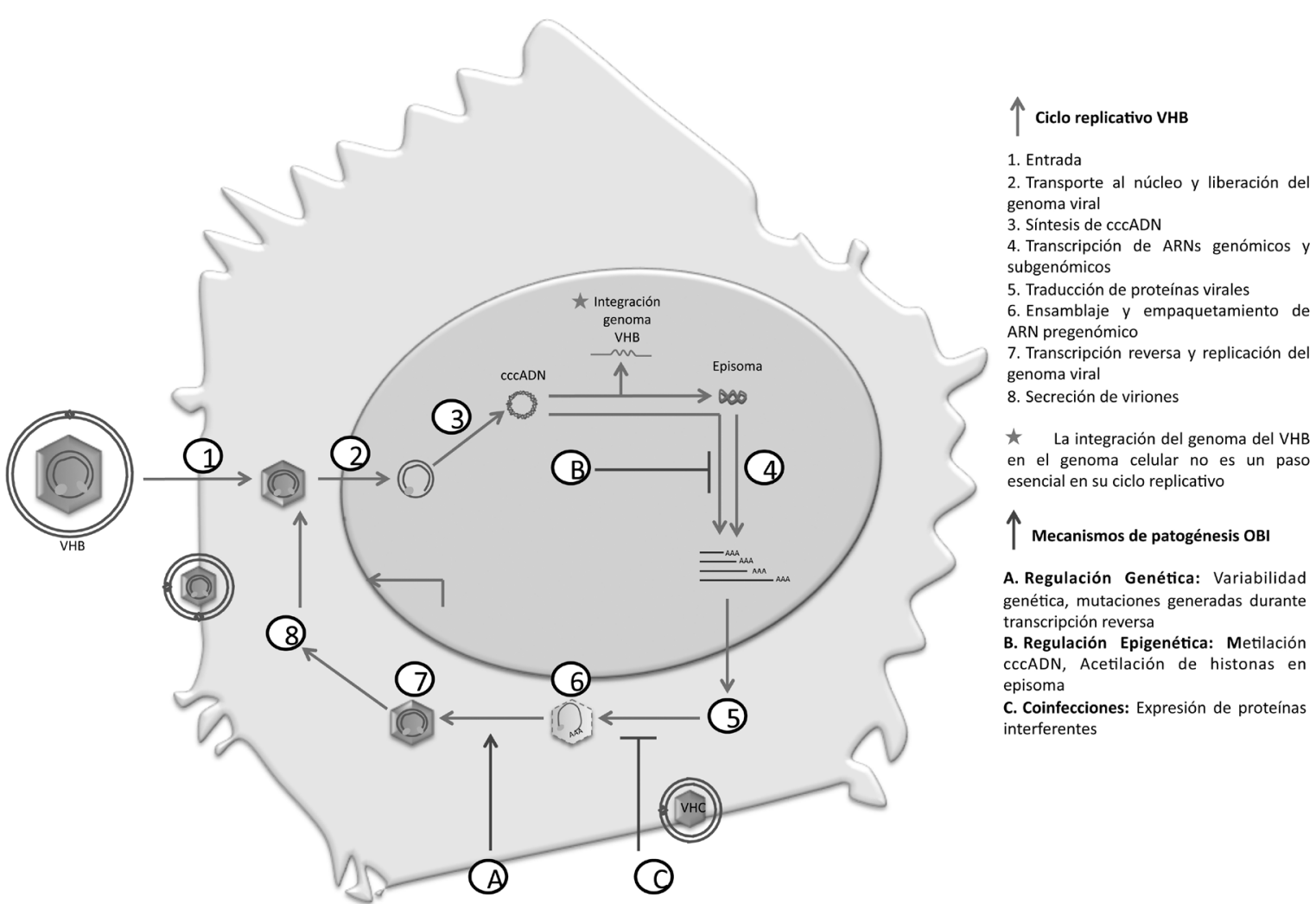

Figura 5. Representación esquemática del ciclo replicativo del VHB y etapas que podrían estar implicadas en los mecanismos moleculares asociados a la OBI. En este gráfico se presenta un esquema de los principales pasos del ciclo replicativo del $\mathrm{VHB}$, indicados con números y flechas rojas. Los mecanismos de patogénesis asociados a la OBI y su efecto sobre la replicación viral se indican con letras $(A, B$ y $C)$ y líneas azules. 
Es importante hacer distinción entre las mutaciones que se generan en el determinante "a" y las que se producen por fuera de éste. En las primeras se puede modificar el epítope reconocido por los anticuerpos neutralizantes y los anticuerpos utilizados en las pruebas de ELISA.

No en todos los casos se evidencia la presencia de mutaciones y/o variantes en el determinante "a" que impidan la detección del HBsAg. Por tal razón, se ha considerado el estudio de otros segmentos como la región pre-S1; esta secuencia contiene un elemento regulador (Promotor preS1), el cual estimula la síntesis del ARN subgenómico de $2.4 \mathrm{~kb}$. Algunas mutaciones en pre-S1 pueden disminuir el nivel de expresión del HBsAg y por tanto afectar la formación de nuevas partículas virales $(29,30)$. Esta hipótesis es validada en parte por el estudio de Cabrerizo y colaboradores, en el que se observa frecuentemente una delección (o pérdida de una parte de esta secuencia) en pre-S1 en aislados del VHB provenientes de pacientes con diagnóstico de OBI; es de anotar que en ninguno de estos aislados se detectaron mutaciones en el segmento $\mathrm{S}$ (31).

En el caso del ORF Core y su promotor también se han descrito mutaciones que podrían estar relacionadas con una baja carga viral $(<200 \mathrm{UI} / \mathrm{mL})$. El cambio más frecuente es la doble mutación T1762A/A1764G, la cual se ha relacionado con la disminución en la síntesis del pgARN y como consecuencia disminución en el nivel de síntesis de Core y la polimerasa y además menor número de copias molde para la generación de nuevos genomas virales (32). La mutación A1896G en la región pre-C modifica la formación de la señal de encapsidación $(\varepsilon)$ en el pgARN, la cual es necesaria para la interacción del pgARN, la polimerasa y Core para la formación de la nucleocápside, en la cual se realiza la síntesis de nuevos genomas virales (33). Por lo anterior, mutaciones en $\mathrm{BCP}$ y pre- $\mathrm{C} / \mathrm{C}$ disminuyen el nivel de expresión del $\mathrm{HBcAg}$ y $\mathrm{HBeAg}$ y hacen menos eficiente la replicación viral (bajo fitness), esto podría correlacionarse con OBI (34).

Otro de los mecanismos que podría estar implicado con la OBI, es la integración del genoma del VHB en el genoma celular; la integración del genoma viral puede resultar en la pérdida de la expresión de antígenos virales como el HBsAg, reducción en la producción de nuevos viriones y disminución de la carga viral. Esto explicaría en parte la no detección del HBsAg y una carga viral $<200 \mathrm{UI} / \mathrm{mL}$ de la OBI (35). La integración del genoma de VHB ocurre como un evento aleatorio en la infección por VHB que puede generar cambios en la secuencia como delecciones (25-45\% de casos CHC asociados a VHB) e inserciones (30-50\% de casos $\mathrm{CHC}$ asociados a VHB) e inestabilidad cromosómica (36). Es de anotar que la integración del genoma del VHB no es un evento necesario para la replicación viral. Aunque es plausible la relación entre integración del genoma del VHB, la persistencia de la infección y el desarrollo de OBI $(18,37)$.

\section{Regulación epigenética del VHB}

La metilación es un mecanismo de regulación de la expresión de los genes, que consiste en la adición de grupos metilo a las citosinas de ciertas secuencias del ADN; esta modificación química puede producir el silenciamiento de un gen. Teniendo en cuenta que el genoma del VHB puede persistir en el núcleo de los hepatocitos en forma de minicromosoma, es posible que la metilación del ADN del VHB represente un mecanismo que puede modificar la replicación y la expresión de proteínas virales. Una evidencia de este mecanismo, es que la metilación de la secuencia que codifica para la proteína Core produce pérdida de expresión de la proteína; esto ha sido demostrado in vitro en una línea celular de hepatoma humano (PLC/PRF/5) (38). Es de anotar que la metilación sería un mecanismo de regulación tanto para secuencias integradas como para el minicromosoma del VHB (39). Es importante mencionar que elementos reguladores del genoma del VHB (promotores y "enhancer") se encuentran localizados en secuencias de ADN ricas en pares citosina y guanina, las cuales son susceptibles de ser metiladas; éstas se conocen como islas CpG (40) (Figura 1). En el genoma del VHB se han identificados tres islas CpG. Se ha descrito que la metilación de la isla CpG II del VHB es frecuente en casos de OBI. Las islas CpG I y III del VHB se han encontrado metiladas en muestras provenientes de pacientes con $\mathrm{CHC}$ asociado al VHB, tanto en secuencias integradas como en el cccADN. Estos hallazgos fueron corroborados por Kaur y colaboradores en muestras de tejido hepático provenientes de pacientes con diagnóstico de CHC. La frecuencia de metilación en la isla CpG I del VHB fue mayor en los casos CHC asociado a OBI, comparado con los casos de $\mathrm{CHC}$ asociados a la infección por VHB con marcador HBsAg positivo (41).

\section{Respuesta inmune e infección oculta por VHB}

Se ha sugerido que la respuesta inmune es diferente entre individuos con OBI e individuos que logran el aclaramiento viral. En estudios recientes, se han evaluado los niveles de citoquinas y quimioquinas en pacientes con OBI y se ha demostrado que estos pacientes presentan mayores niveles de interleuquina-10 (IL-10) e IL-17A, comparado con pacientes con resolución de la infección y controles sanos. La IL-10 es considerada una de las principales citoquinas involucradas en la regulación negativa de la respuesta inmune celular contra las infecciones virales, mientras que, la IL-17A inhibe la apoptosis de hepatocitos infectados, por lo que favorece la persistencia del VHB; además la IL-17 tiene un efecto antagonista sobre la IL-12 y la expresión de interferón $\gamma($ INF- $\gamma)$. Se ha observado que pacientes con OBI no presentan diferencias significativas en la expresión de IL-12 comparado con individuos sanos y con infección resuelta, por el contrario los niveles de IL-10, IL-17 e INF- $\gamma$ son reducidos (42-44). 
Factores genéticos relacionados con el hospedero podrían interferir con la expresión de citoquinas, por lo que se podrían correlacionar con la falta del aclaramiento viral en OBI. Estudios recientes han demostrado diferencias significativas en los genes que codifican para las citoquinas SDF-1 $\alpha$ (Factor derivado de células estromales-1 $\alpha$ ) e IL12 en pacientes con OBI, comparado con individuos sanos o con casos de infección con resolución (44). Así mismo, también se han identificado polimorfismos (variaciones en la secuencia de ADN en un lugar determinado del genoma entre los individuos de una población) en la región promotora del gen que codifica para la IL-10 y en el gen que codifica para el receptor de vitamina $\mathrm{D}$, los cuales podrían estar relacionados con la OBI (45).

Respecto a la inmunidad humoral, estudios previos han demostrado que anticuerpos anti-HBs desempeñan una importante función en la protección de individuos infectados por el VHB (46). Investigaciones realizadas en pacientes con OBI han demostrado que los niveles en suero de inmunoglobulina $\mathrm{G}$ ( $\mathrm{IgG}$ ) y el factor $\mathrm{C} 4 \mathrm{del}$ sistema complemento, son significativamente menores en pacientes con OBI comparado con casos con aclaramiento viral (44). Así mismo, se ha descrito que pacientes con $\mathrm{OBI}$ con anti-HBc detectables en suero tienen una respuesta eficiente de células $\mathrm{T}$ de memoria, lo cual se asocia a memoria protectora; mientras que pacientes con OBI negativos para anti-HBc presentan una inadecuada maduración de células T de memoria (47).

El número reducido de células mononucleares de sangre periférica (PBMC, siglas en inglés Peripheral Blood Mononuclear Cells), específicamente linfocitos T y células NK puede llevar a la atenuación de la respuesta inmune contra el VHB. Aunque algunos estudios han evidenciado que el número de PBMC y en particular de células NK no está alterado en casos de OBI, el número de linfocitos T $\mathrm{CD}^{+}$se encuentra disminuido en pacientes con OBI (44). Aunque este es un tema que aun continúa en experimentación, se sugiere que aspectos relacionados con la función de los linfocitos T, tales como migración, reconocimiento de antígenos, activación y proliferación, son defectuosos durante la OBI.

\section{Coinfecciones}

La interferencia viral parece ser un factor que podría regular negativamente la replicación y expresión de genes del VHB. En particular, las coinfecciones con VHC y VIH parecen tener una fuerte implicación no sólo epidemiológica, sino también en la patogénesis de la entidad (Figura 4).

La coinfección del VHB y el VHC ha sido ampliamente documentada (20). Según lo reportado, 65\% de los individuos infectados por VHC presentan OBI $(48,49)$. Cacciola y colaboradores encontraron una alta frecuencia de OBI en pacientes con infección crónica por VHC y un mayor número de casos con cirrosis en pacientes crónicamente infectados por VHC con OBI (33\%), comparado con los pacientes infectados por el VHC sin OBI (19\%) (50). En otro estudio, se demostró que pacientes con coinfección por VHC y OBI tienen menor respuesta al tratamiento con INF, comparado con pacientes infectados sólo por VHC; no obstante se requieren más estudios para determinar si la OBI puede estar asociada con la resistencia al tratamiento con INF (51).

La interferencia de la replicación del VHB por el VHC ha sido atribuida a la proteína core del VHC, la cual tiene la capacidad de inhibir la replicación y expresión de genes del VHB; además suprime la actividad de los elementos potenciadores del VHB $(52,53)$. También se ha demostrado que la proteína core del VHC se une con la polimerasa del VHB e interfiere con el reconocimiento de la señal de encapsidación (52). Además, la proteína core interacciona con la proteína HBx e inhibe su función como transactivador (52). Así mismo, la proteína NS2 del VHC inhibe la secreción del HBsAg y el HBeAg en ensayos in vitro (54).

Con respecto a la coinfección VHB/VIH, la prevalencia reportada de $\mathrm{OBI}$ en pacientes infectados con VIH varía de 0\%-89\% según el método de detección del ADN del VHB y la historia de tratamiento antirretroviral (Tabla 2) (20, 55). Sin embargo, los mecanismos específicos que llevan a la OBI en pacientes con infección por VIH no se conocen.

\section{Conclusión}

El fenómeno de la infección oculta por el VHB se caracteriza por una marcada inhibición de la replicación viral y de la expresión de genes del VHB. Para su diagnóstico se requiere de técnicas de biología molecular sensibles y específicas. Pese al gran número de incógnitas que aún permanecen sin resolver al respecto, es importante resaltar los estudios de exploración de los mecanismos de patogénesis de la OBI y de la epidemiología de esta entidad. Sin embargo, estudios adicionales son requeridos para explicar esta particular forma de infección; las hipótesis propuestas y cada una de las evidencias que a la fecha sustentan la OBI sugieren que esta es una entidad multifactorial. Muy posiblemente algunos de los mecanismos que se proponen están relacionados con la OBI tengan una mayor relevancia que otros. En este sentido los mecanismos epigenéticos que explican el desarrollo de la entidad y los factores que influyen en la producción del cccADN y su persistencia en el núcleo del hepatocito serían los factores más importantes. La identificación de marcadores epigenéticos como por ejemplo, la identificación de islas $\mathrm{CpG}$ metiladas del cccADN del VHB y la definición precisa de las actividades enzimáticas celulares que modulan la transcripción del minicromosoma, así como las vías de señalización que modulan su actividad, abren nuevas perspectivas para la identificación de blancos terapéuticos que supriman permanentemente la transcripción y replicación del genoma del VHB. Por otro lado, se debe continuar con el esfuerzo para entender las bases moleculares que se relacionan con el ciclo replicativo del VHB y la interacción con los factores del hospedero que estarían influyendo. 
En conclusión, la OBI es una entidad que impacta diversos aspectos clínicos y epidemiológicos como la transmisión de la infección por productos sanguíneos y/o el trasplante de órganos, lo que sugiere la idea que la proporción de individuos infectados por VHB podría superar la cifra de 350 millones de individuos crónicamente infectados, lo cual revela el verdadero impacto en la salud pública a nivel mundial y la necesidad de investigar en pro de la identificación de alternativas terapéuticas que disminuyan su prevalencia.

\section{Declaración conflictos de interés}

Este trabajo no ha sido presentado ni publicado anteriormente, no existen conflictos de tipo financiero, ni de interés actuales o potenciales relacionados con este manuscrito.

\section{Agradecimientos}

Programa de sostenibilidad, Vicerrectoría de Investigación, Universidad de Antioquia. Instituto Tecnológico Metropolitano. Dirección de Investigación, Instituto Tecnológico Metropolitano (ITM), Institución Universitaria Adscrita a la Alcaldía de Medellín, proyecto P09207.

\section{Referencias}

1. Seeger C. and W.S. Mason. Hepatitis B virus biology. Microbiol Mol Biol Rev 2000; 64(1): 51-68.

2. Hoofnagle J.H. Serologic markers of hepatitis B virus infection. Annu Rev Med 1981; 32: 1-11.

3. Knipe D.M. and P.M. Howley. Fields Virology. 5th Edition. 2007.

4. Prince,A.M, D.H. Lee, and B. Brotman. Infectivity of blood from PCR-positive, HBsAg-negative, anti-HBs-positive cases of resolved hepatitis B infection. Transfusion 2001; 41(3): 329-32.

5. Tabor, E. and R.J. Gerety. Transmission of hepatitis B by immune serum globulin. Lancet 1979; 2(8155): 1293.

6. Raimondo G, et al. A 2010 update on occult hepatitis B infection. Pathol Biol 2010; 58(4): 254-7.

7. Hu K.Q. Occult hepatitis B virus infection and its clinical implications. $J$ Viral Hepat 2002; 9(4): 243-57.

8. Michalak T.I, P.M Mulrooney, and C.S. Coffin. Low doses of hepadnavirus induce infection of the lymphatic system that does not engage the liver. $J$ Virol 2004; 78(4): 1730-8

9. Raimondo G, et al. Statements from the Taormina expert meeting on occult hepatitis B virus infection. J Hepatol 2008; 49(4): 652-7.

10. Hoofnagle J.H, et al. Type B hepatitis after transfusion with blood containing antibody to hepatitis B core antigen. N Engl J Med 1978; 298(25): 1379-83.

11. Thiers $\mathbf{V}$, et al. Transmission of hepatitis B from hepatitis-B-seronegative subjects. Lancet 1988; 2(8623): 1273-6.

12. Comanor L. and P. Holland. Hepatitis B virus blood screening: unfinished agendas. Vox Sang 2006; 91(1): 1-12.

13. Beltran M, et al. Detección de hepatitis B oculta en donantes de bancos sangre, Colombia 2008-2009. Biomédica 2011; 31(4).

14. Samuel D, et al. Report of the monothematic EASL conference on liver transplantation for viral hepatitis (Paris, France, January 12-14, 2006). J Hepatol 2006; 45(1): $127-43$.

15. Hollinger F.B. and G. Sood. Occult hepatitis B virus infection: a covert operation. J Viral Hepat 2010 17(1): 1-15.

16. Wachs M.E, et al. The risk of transmission of hepatitis B from HBsAg(-), HBcAb(+), HBIgM(-) organ donors. Transplantation 1995; 59(2): 230-4.

17. Satterthwaite R, et al. Risks of transplanting kidneys from hepatitis B surface antigen-negative, hepatitis B core antibody-positive donors. Transplantation 1997; 64(3): 432-5.

18. Raimondo G, et al. Occult hepatitis B virus infection. J Hepatol 2007; 46(1): 160-70.

19. Berasain C, et al. Pathological and virological findings in patients with persistent hypertransaminasaemia of unknown aetiology. Gut 2000 47(3): 429-35.

20. Samal J, M Kandpal, and P Vivekanandan. Molecular mechanisms underlying occult hepatitis B virus infection. Clin Microbiol Rev 2012; 25(1): 142-63.

21. Chemin I, et al. Role of silent hepatitis B virus in chronic hepatitis B surface antigen(-) liver disease. Antiviral Res 2001; 52(2): 117-23.

22. Ramírez, I. and J. Cataño. Prevalencia de hepatitis B oculta en una cohorte prospectiva de pacientes con VIH. Iatreia 2008. 21(1S).
23. Polo P., et al. Hepatitis B oculta en pacientes VIH positivos de una institución de salud en Barranquilla Colombia. Infectio 2009; 14(1): 39-46.

24. Arroyave J. and F. Cortes-Mancera. Caracterizacion molecular de la infeccion por el virus de la hepatitis B en donantes de sangre HBsAg negativo/anti-HBc positivo. Memorias IV simposio nacional de virologia, 2011.

25. Lee W.M. Hepatitis B virus infection. N Engl J Med 1997; 337(24): 1733-45.

26. Beck, J. and M. Nassal. Hepatitis B virus replication. World J Gastroenterol 2007. 13(1): 48-64.

27. Weber B. Genetic variability of the $S$ gene of hepatitis B virus: clinical and diagnostic impact. J Clin Virol 2005; 32(2): 102-12.

28. Yuh, C.H., Y.L. Chang, and L.P. Ting. Transcriptional regulation of precore and pregenomic RNAs of hepatitis B virus. J Virol 1992; 66(7): 4073-84.

29. Cheng K.C., G.L. Smith, and B. Moss. Hepatitis B virus large surface protein is not secreted but is immunogenic when selectively expressed by recombinant vaccinia virus. J Virol 1986; 60(2): 337-44.

30. Chisari F.V, et al. Structural and pathological effects of synthesis of hepatitis B virus large envelope polypeptide in transgenic mice. Proc Natl Acad Sci U S A 1987; 84(19): 6909-13.

31. Cabrerizo M, et al. Molecular analysis of hepatitis B virus DNA in serum and peripheral blood mononuclear cells from hepatitis B surface antigen-negative cases. Hepatology 2000; 32(1): 116-23.

32. Parekh S, et al. Genome replication, virion secretion, and e antigen expression of naturally occurring hepatitis B virus core promoter mutants. J Virol 2003; 77(12): 6601-12.

33. Kidd-Ljunggren K, Y Miyakawa, and A.H. Kidd Genetic variability in hepatitis B viruses. J Gen Virol 2002; 83(Pt 6): 1267-80.

34. Kramvis A. and M.C. Kew. Relationship of genotypes of hepatitis B virus to mutations, disease progression and response to antiviral therapy. $J$ Viral Hepat 2005; 12(5): 456-64.

35. Hsia C.C,Y.Nakashima, and E. Tabor. Deletion mutants of the hepatitis B virus X gene in human hepatocellular carcinoma. Biochem Biophys Res Commun 1997. 241(3): 726-9.

36. Zhang $\mathbf{X}$., et al. Hepatitis B virus X protein upregulates survivin expression in hepatoma tissues. J Med Virol 2005; 77(3): 374-81.

37. Murakami Y, et al. Large scaled analysis of hepatitis B virus (HBV) DNA integration in HBV related hepatocellular carcinomas. Gut 2005; 54(8): 1162-8.

38. Miller R.H. and W.S. Robinson. Integrated hepatitis B virus DNA sequences specifying the major viral core polypeptide are methylated in PLC/PRF/5 cells. Proc Natl Acad Sci U S A 1983; 80(9): 2534-8.

39. Pollicino T, et al. Hepatitis B virus replication is regulated by the acetylation status of hepatitis B virus cccDNA-bound $\mathrm{H} 3$ and $\mathrm{H} 4$ histones. Gastroenterology 2006; 130(3): 823-37.

40. Vivekanandan $\mathbf{P}$, et al. Comprehensive genetic and epigenetic analysis of occult hepatitis B from liver tissue samples. Clin Infect Dis 2008; 46(8): 1227-36.

41. Kaur P, et al. DNA methylation of hepatitis B virus (HBV) genome associated with the development of hepatocellular carcinoma and occult HBV infection. $J$ Infect Dis 2010; 202(5): 700-4.

42. Arababadi M.K, et al. Serum Levels of IL-10 and IL-17A in Occult HBV-Infected South-East Iranian Patients. Hepat Mon 2010; 10(1): 31-5.

43. Lemos H.P, et al. Prostaglandin mediates IL-23/IL-17-induced neutrophil migration in inflammation by inhibiting IL-12 and IFNgamma production. Proc Nat Acad Sci U S A 2009; 106(14): 5954-9.

44. Arababadi M.K., B. Nasiri Ahmadabadi, and D. Kennedy. Current information on the immunologic status of occult hepatitis B infection. Transfusion 2012; 52(8): $1819-26$.

45. Arababadi M.K, et al. Association of exon 9 but not intron 8 VDR polymorphisms with occult HBV infection in south-eastern Iranian patients. J Gastroenterol Hepatol 2010; 25(1): 90-3.

46. Calmus Y, et al. Distribution of hepatitis B virus DNA sequences in different peripheral blood mononuclear cell subsets in HBs antigen-positive and negative patients. Eur J Clin Invest 1994; 24(8): 548-52.

47. Zerbini A, et al. The characteristics of the cell-mediated immune response identify different profiles of occult hepatitis B virus infection. Gastroenterology 2008; 134(5): 1470-81.

48. Squadrito G, et al. Occult hepatitis B virus infection is associated with the development of hepatocellular carcinoma in chronic hepatitis $\mathrm{C}$ patients. Cancer 2006 106(6): 1326-30.

49. Matsuoka S, et al. Influence of occult hepatitis B virus coinfection on the incidence of fibrosis and hepatocellular carcinoma in chronic hepatitis C. Intervirology 2008; 51(5): 352-61.

50. Cacciola I, et al. Occult hepatitis B virus infection in patients with chronic hepatitis C liver disease. $N$ Engl J Med 1999; 341(1): 22-6. 
51. Fabris P, et al. Occult hepatitis B virus infection does not affect liver histology or response to therapy with interferon alpha and ribavirin in intravenous drug users with chronic hepatitis C. J Clin Virol 2004; 29(3): 160-6.

52. Chen S.Y, et al. Mechanisms for inhibition of hepatitis B virus gene expression and replication by hepatitis C virus core protein. J Biol Chem 2003; 278(1): 591-607.

53. Schuttler C.G, et al. Suppression of hepatitis B virus enhancer 1 and 2 by hepatitis C virus core protein. J Hepatol 2002; 37(6): 855-62.

54. Dumoulin F.L, et al. Hepatitis C virus NS2 protein inhibits gene expression from different cellular and viral promoters in hepatic and nonhepatic cell lines. Virology 2003; 305(2): 260-6.

55. Hofer M, et al. Frequent chronic hepatitis B virus infection in HIV-infected patients positive for antibody to hepatitis B core antigen only. Swiss HIV Cohort Study. Eur J Clin Microbiol Infect Dis 1998; 17(1): 6-13.

56. Besisik F, et al. Occult HBV infection and YMDD variants in hemodialysis patients with chronic HCV infection. J Hepatol 2003; 38(4): 506-10.

57. Toyoda $\mathbf{H}$, et al. Prevalence and clinical implications of occult hepatitis B viral infection in hemophilia patients in Japan. J Med Virol, 2004. 73(2): p. 195-9.

58. Fabrizi, F., et al., Occult hepatitis B virus infection in dialysis patients: a multicentre survey. Aliment Pharmacol Ther 2005; 21(11): 1341-7.

59. Kanbay M, et al. Is hepatitis C virus positivity a contributing factor to occult hepatitis B virus infection in hemodialysis patients? Dig Dis Sci 2006; 51(11): 1962-6.

60. Goral V, et al. Prevalence of occult HBV infection in haemodialysis patients with chronic HCV. World J Gastroenterol 2006; 12(21): 3420-4.

61. Altindis M, et al. (Investigation of hemodialysis patients in terms of the presence of occult hepatitis B). Mikrobiyol Bul 2007; 41(2): 227-33.

62. Filippini P, et al. Impact of occult hepatitis B virus infection in HIV patients naive for antiretroviral therapy. AIDS 2006; 20(9): 1253-60.

63. Rai R.R, et al. Prevalence of occult hepatitis B \& C in HIV patients infected through sexual transmission. Trop Gastroenterol 2007; 28(1): 19-23.

64. Tsui J.I, et al. Prevalence and long-term effects of occult hepatitis B virus infection in HIV-infected women. Clin Infect Dis 2007; 45(6): 736-40.

65. Nebbia G, et al. Predictors and kinetics of occult hepatitis B virus infection in HIV-infected persons. J Med Virol 2007; 79(10): 1464-71.

66. Quarleri J, et al. Hepatitis B virus genotype distribution and its lamivudineresistant mutants in HIV-coinfected patients with chronic and occult hepatitis B. AIDS Res Hum Retroviruses 2007; 23(4): 525-31.

67. Torbenson M, et al. High prevalence of occult hepatitis B in Baltimore injection drug users. Hepatology 2004; 39(1): 51-7.
68. Lin C.L, et al. High prevalence of occult hepatitis B virus infection in Taiwanese intravenous drug users. J Med Virol 2007; 79(11): 1674-8.

69. Ferreira R.C, et al. Prevalence of hepatitis B virus and risk factors in Brazilian non-injecting drug users. J Med Virol 2009; 81(4): 602-9.

70. Paterlini P, et al. Polymerase chain reaction to detect hepatitis B virus DNA and RNA sequences in primary liver cancers from patients negative for hepatitis B surface antigen. N Engl J Med 1990 323(2): 80-5.

71. Matsuzaki Y, et al. The role of previous infection of hepatitis B virus in Hbs antigen negative and anti-HCV negative Japanese patients with hepatocellular carcinoma: etiological and molecular biological study. J Exp Clin Cancer Res 1999; 18(3): 379-89.

72. Kew M.C, R Welschinger, and R Viana. Occult hepatitis B virus infection in Southern African blacks with hepatocellular carcinoma. J Gastroenterol Hepatol 2008; 23(9): 1426-30.

73. Tamori A, et al. Frequent detection of hepatitis B virus DNA in hepatocellular carcinoma of patients with sustained virologic response for hepatitis $\mathrm{C}$ virus. $J$ Med Virol 2009; 81(6): 1009-14.

74. Kaviani M.J, et al. Occult hepatitis B virus infection and cryptogenic chronic hepatitis in an area with intermediate prevalence of HBV infection. World $J$ Gastroenterol 2006; 12(31): 5048-50.

75. Fang Y, et al. Prevalence of occult hepatitis B virus infection among hepatopathy patients and healthy people in China. J Infect 2009; 58(5): 383-8.

76. Kao J.H, et al. Occult hepatitis B virus infection and clinical outcomes of patients with chronic hepatitis C. J Clin Microbiol 2002; 40(11): 4068-71.

77. Torbenson M. and D.L. Thomas. Occult hepatitis B. Lancet Infect Dis 2002; 2(8): 479-86.

78. Branco F, et al. Occult hepatitis B virus infection in patients with chronic liver disease due to hepatitis $\mathrm{C}$ virus and hepatocellular carcinoma in Brazil. Arq Gastroenterol 2007; 44(1): 58-63.

79. Bhatti F.A, et al. Anti-hepatits B core antigen testing, viral markers, and occult hepatitis B virus infection in Pakistani blood donors: implications for transfusion practice. Transfusion 2007 ;47(1): 74-9.

80. Bhattacharya P, et al. Significant increase in HBV, HCV, HIV and syphilis infections among blood donors in West Bengal, Eastern India 2004-2005: exploratory screening reveals high frequency of occult HBV infection. World J Gastroenterol 2007; 13(27): 3730-3.

81. Allain J.P, et al. Characterization of occult hepatitis B virus strains in South African blood donors. Hepatology 2009; 49(6): 1868-76. 